
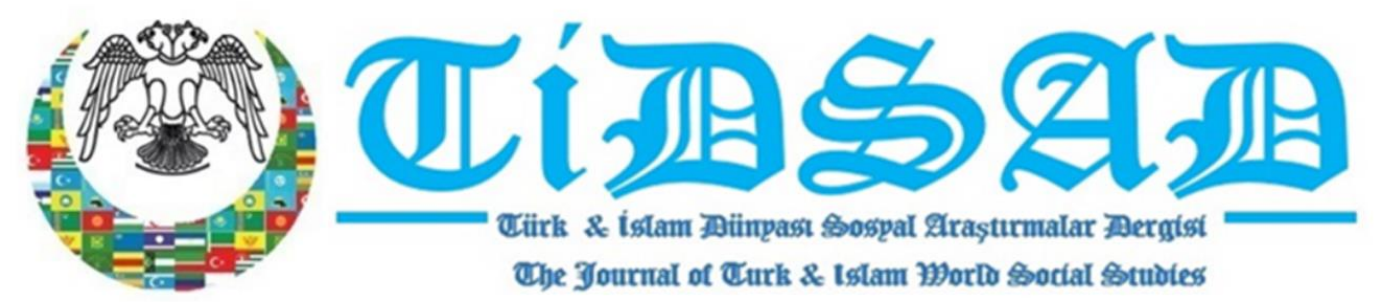

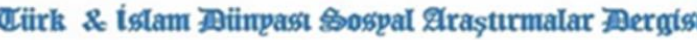

The Journal of Turk \& tstam Morlo Sotal Stưtes

\section{Orhun Yazitlarının Transkripsiyon Farklılıkları}

\section{Transcription Differences of Orhun Instructions}

\title{
Bayram BíLíR*
}

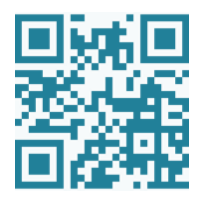

Geliş/Submitted:

12.11.2021

Kabul/Accepted:

22.12 .2021

Yayın/Published:

Citation / Atıf

Bilir, B. (2021). Orhun Yazıtlarının Transkripsiyon Farklılıkları. Türk \& İslam Dünyası Sosyal Araştırmalar Dergisi, 8 (31), 187-203.

Bilir, B. (2021). Transcription Differences of Orhun Instructions. The Journal of Turk \& Islam World Social Studies, 8 (31), 187-203.

Makale Türü:

Araştırma Makalesi
Article Information:

\section{Research Article}

This article was checked by Intihal.net. Bu makale İntihal.net tarafindan taranmıştır.

This article is under the Creative Commons license. Bu makale Creative Commons lisansı altındadır.

*Öğr. Gör., Semerkant Devlet Yabancı Diller Enstitüsü, bayrambilir33@hotmail.com 


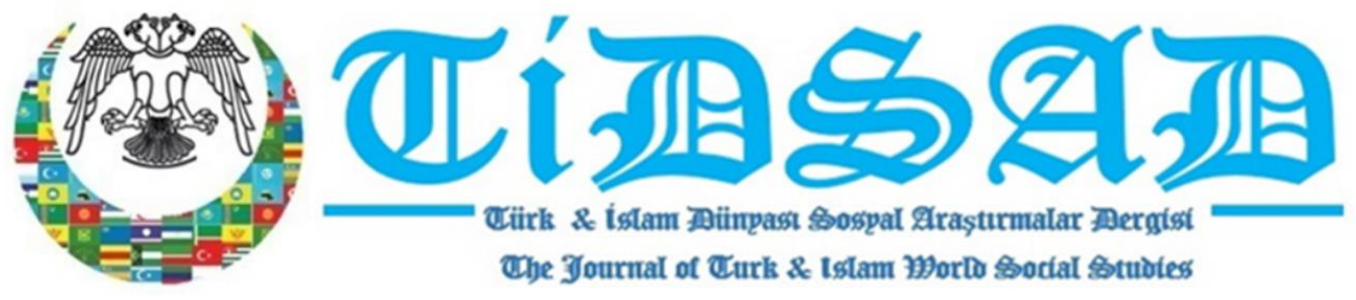

Orhun Yazıtlarının Transkripsiyon Farklılıkları ${ }^{1}$

Transcription Differences of Orhun Instructions

\author{
Öğr. Gör. Bayram BİLİR
}

Öz: Orhun Yazıtları olarak adlandırdığımız Kül Tekin, Bilge Kağan ve Tonyukuk Yazıtlarının yazımında kullanılan Köktürk alfabesinde 4 işaret ikişer ünlüyü ( $\sqrt{ }$ a-e,$\uparrow$ 1-i, $>$ u-o, $N$ ö-ü) göstermek için kullanılır. 31 işaretten 20 'si in-

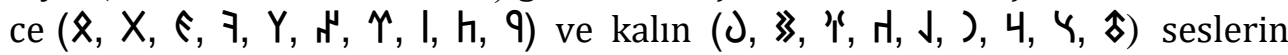
ayrımını gösterirken 7 harf yansız harfleri $(\lambda, \otimes, \uparrow, \xi, 1,7,4), 4$ harf ise ünlü-ünsüz ve ünsüz-ünlü $(\downarrow, F, \triangleleft, \Psi)$ değerinde harfleri göstermektedir. 38 harften oluşan Köktürk alfabesinde üç harf ise çift ünsüzler olarak ifade edilmektedir. Çift ünsüzlerden oluşan harflerle beraber yansız ünsüz kabul edilen $\downarrow, \downarrow, F, \triangleleft, \mathcal{Y}$ ve $\exists$ işaretleri üzerine Türkologlar tarafından yapılan transkripsiyonlar incelendiğinde çeșitli varyantların oluștuğu gözlemlenmektedir. Bu çalışmamızda Orhun Yazıtları üzerine eserler veren Türkologların yazıtlarda kullanılan harfleri nasıl transkribe ettikleri incelenecek ve Uluslararası Fonetik Cemiyetinin tavsiye ettiği IPA alfabesine göre tekrar yorumlanacaktır.

Anahtar Kelimeler: Orhun Yazitları, transkripsiyon, IPA.

Abstract: In the Köktürk alphabet used in the writing of the Kül Tekin (1968: 229-253), Bilge Kagan and Tonyukuk Inscriptions, which we call the Orkhon Inscriptions, 4 signs are used to show two vowels each $\left(\sqrt{ } \mathrm{a}-\mathrm{e}, \Gamma_{1-\mathrm{i}}>\mathrm{u}-\mathrm{o}, \mathrm{N}\right.$ ö-ü). 20 out of 31 signs show the distinction thin sounds ( $\boldsymbol{X}, X, \hat{F}, \mathcal{7}, \mathbf{Y}, \boldsymbol{\mu}, \boldsymbol{\Upsilon}$,

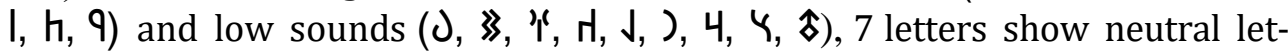
ters $(\lambda, \gg, \nsucc, 3,1, \nsucceq, 4)$, 4 letters show vowel-consonant and consonantvowel-valued letters $(\downarrow, F, \triangleleft, \Psi)$. In the Köktürk alphabet, which consists of 38 letters, three letters are expressed as double consonants $(M, 3, \odot)$. When the transcriptions made by Turcologists on the $\mathcal{\Psi}, \downarrow, F, \triangleleft, \mathcal{Y}$ and $\xi$ signs, which are accepted as vowel-consonant and consonant-vowel letters, except for letters consisting of double consonants, various variants are observed. In this study, it will be examined how the Turcologists, who work on the Orkhon Inscriptions and how they transkribe the letters used in the inscriptions, and

1 “COPE-Dergi Editörleri İçin Davranış Kuralları ve En İyi Uygulama İlkeleri” beyanları: Bu çalışma için herhangi bir çıkar çatışması bildirilmemiştir. Bu çalışma için etik kurul onayı gerekmemektedir. Sorumlu Yazar: Cemil İNAN

Statements of "COPE-Code of Conduct and Best Practices Guidelines for Journal Editors": No conflicts of interest were reported for this article. Ethics committee approval is not required for this article. Corresponding Author: Cemil İNAN 
will be reinterpreted according to the IPA alphabet recommended by the International Phonetic Society.

Keywords: Orkhon Inscriptions, transcription, IPA.

\section{GíRiş}

Orhun yazıtları 18. yüzyıl başlarında Ruslara esir düşen Johann von Strahlenbeg'in eseri aracılığıyla biliniyordu. Araştırma amacıyla ilk bilimsel heyetler ancak 19. yüzyılın sonlarında gönderilebilmişti. İlk heyetler 1889-1888'de gönderilen Fin araştırma heyetleriydi. Yazitlar keşfedildikten sonra Rusya, Almanya, Türkiye, Kazakistan, Özbekistan, Azerbaycan, Kırgızistan, Çin ve Macaristan gibi devletlerde Yadrintsev, Thomsen, Radlov, Vambery, Melioransky, Orkun, Gabain, Malov, Tekin, Ergin, Aydarov, AbdurrahmanovRüstemov, Şükürov, Memmedov, Sıdıkov-Konkobaev, Amanjolov, Sodikov, Bazylkhan, Geng, Tugușeva, Berta, Karcaubay, Hudiyev, Ercilasun, Aydın gibi bilim insanları tarafından dilbilimsel olarak birçok akademik araştırmaya konu edilmiştir.

Yazıtlar üzerine yapılan araştırmaların günümüze kadar çoğunlukla okuma ve anlamlandırma farklılıkları üzerine yoğunlaştığı gözlemlenmektedir. Kavramsal ve içerik olarak da birçok çalışmaya kaynak olan yazıtlar, üzerinde yapılan ve yapılacak olan çalışmalar Yakutça ve Çuvaşça dışında tüm tarihi ve Çağdaş Türk dillerinin birincil kaynak olması bakımından da önemlidir.

Yazıtlarda kullanılan işaretlerin günümüzde kullanılmıyor olması ve okuma ve anlamlandırmayı güçleştirdiği gerçeği araştırmacıları yeni bakış açılarına yönelmeye sevk etmektedir. Okuma ve anlamlandırma çalışmalarından önce, yazıtların tam anlamıyla doğru transkripsiyonunun yapılamadığı fikrindeyiz. Köktürk alfabesinde 4 işaret ikişer ünlüyü

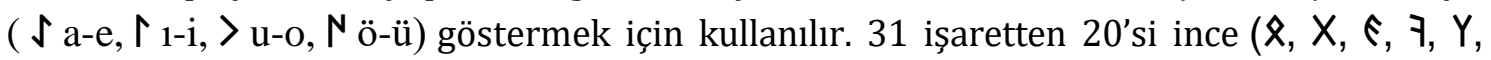

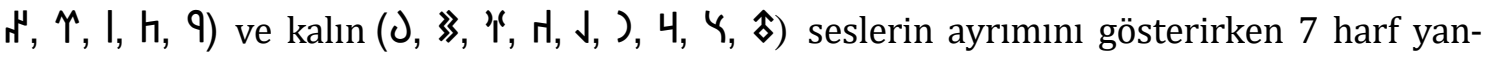
siz harfleri $(\lambda, \diamond, \dashv, 3,1, \nsucc, 4)$ göstermektedir. Nötr işaretlerin transkripsiyonunda bir farlılı̆̆ın oluşması beklenmezken, kalın-ince ünsüzleri aynı harflerle transkribe etmek ne kadar doğrudur? Ünsüzlerin yanına gelen ünlü harflere bakarak ünsüzün kalın veya ince olduğunu tayin edebiliyoruz. Ancak yazıtların genel sistemi ve kuralları hakkında bilgi sahibi olmayan bir kişi yazıtları okurken zorlanacaktır. Örnek vermek gerekirse $Y$ ve $\checkmark$ işaretini transkribe ederken her ikisini de "l" olarak işaretlemek doğru mudur? Başka bir örnek verirsek çift ünsüzleri gösteren işaretlerin transkripsiyonunu okuyan bir araştırmacl "üçinç" okuduğu sözün bengü taş metinlerinde $\lambda_{n}{ }^{N} \lambda \mathrm{N}$ mi yoksa $3 \lambda \mathrm{N}$ olarak mı yazıldığını doğru bilmekte midir?

\section{Yazıtlar Nasıl Transkribe Edildi ve Nasıl Edilmeli?}

Girişte belirttiğimiz zorlukları göz önünde bulundurarak problem olarak düşündüğümüz aşağıdaki soruları hazırlamak ve bu sorulara cevap aranması doğru olacaktır.

1. Ünlü harfler $(\uparrow, \uparrow,>, N)$ Türkologlar tarafından nasıl traskribe edilmiş ve nasıl trankribe edilmeli?

2. Kalın ve ince ünlülerle kullanılan ünsüzler nasıl transkribe edilmiş ve nasıl

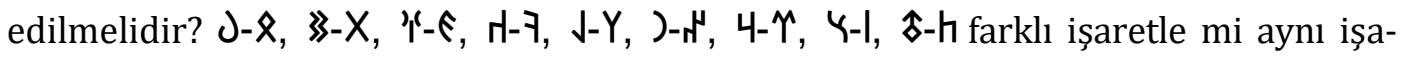


retle mi transkribe edilmiş?

3. Nötr ünsüzler nasıl trankribe edilmiş?

4. Ünlü-ünsüz veya ünsüz-ünlü değerinde olan $\downarrow$, F-B,, , $\Psi$ harflere ait Vokal+Konsonant Konsonant+Vokal yapıları ayrı ayrı işaretlerle mi yoksa tek işaretle mi transkribe edilmiş?

5. Ligatürler olarak adlandırılan $M, 3, \odot$ birliktelikleri ayrı ayrı mı yoksa tek işaretle mi transkribe edilmiş?

6. Yazıtlarda yazılmayan ünlülerin tanskripsiyonu nasıl yapılmış?

$\mathrm{Bu}$ sorular özelinde yazıtlar üzerine çalışan bilim adamlarının eserlerini incelememiz ve IPA (https://www.internationalphoneticassociation.org/content/full-ipachart) standartlarına göre yorumlamamız gerektiğini düşündük.

\section{1. Ünlü harfler $(\uparrow, \uparrow,>, N)$}

\subsubsection{I nasıl transkribe edilmiştir?}

Türkologlar tarafından $\checkmark$ nasıl transkribe edildiği incelenerek yorumlanmış ve önerilerde bulunulmuştur. Bu doğrultuda:

$\checkmark$ harfini kalın ünlü olarak belirtmek için Radlov (1895: 5-83), Thomsen (1896: $97-$ 133), Vambery (1898: 26-85), Melioransky (1899: 60-79), Orkun (1936: 22-121), Gabain (1950: 247-258), Malov (1951: 27-70), Tekin (1968: 229-253), Ergin (2008: 2-81), Aydarov (1971: 286-334), Abdurrahmanov-Rüstemov (1982: 101-114), Şükürov (1993: 218268), Recebov-Memmedov (1993: 70-153), Sidıkov-Konkobaev (2001: 54-95), Amanjalov (2003: 154-180), Sadıkov (2004: 76-120), Bazılkan (2005: 63-118), Geng (2005: 94-223), Berta (2010: 127-189), Karcubay (2012: 165-237), Hudiyev (2015: 188-237), Ercilasun (2016: 499-629) ve Aydın (2017: 47-119) eserlerinde a olarak transkribe etmişlerdir. Kiril ve Latin alfabesinde $\checkmark$ aynı işaretle gösterildiği için bu harfte farklı temayül yoktur. IPA alfabesinde de açık ön düz ünlü a olması gerekliliği tavsiye edilmiştir. Bize göre de $\checkmark$ kalın ünlü olarak a şeklinde transkribe edilmelidir. Aslî uzun ünlü a sesi için de IPA'nın tavsiye ettiği /a:/ șekil kullanılmalıdır.

$\checkmark$ harfini ince ünlü olarak belirtmek için Radlov (1895: 5-83), Thomsen (1896: 97133), Vambery (1898: 26-85), Melioransky (1899: 60-79), Gabain (1950: 247-258), Malov (1951: 27-70), Tekin (1968: 229-253), Abdurrahmanov-Rüstemov (1982: 101-114), Şükürov (1993: 218-268), Amanjalov (2003: 154-180), Sadıkov (2004: 76-120), Geng (2005: 94-223), ve Hudiyev (2015: 188-237), eserlerinde ä olarak transkribe etmişlerdir. $\ddot{\mathrm{A}}$ harfi, Türk dilleri tarafından kullanılan alfabeler içerisinde Tatarca'da, Gagavuzca'da ve Türkmence'de kullanılır. Azericede ə harfine denk gelir. Kısa, kapalı, gırtlaktan gelen ve sert bir e harfidir. Normal e harfine göre daha kısa ve serttir. Ayrıca a ve e arası bir ses olarak öngörülür. Vambery (1898: 26-85), ince ünlüyü belirtmek için bazı örneklerde e harfini de kullanmıștır. Orkun (1936: 22-121), Ergin (2008: 2-81), Tekin (2010: 20-69), Aydarov (1971: 286-334), Sidıkov-Konkobaev (2001: 54-95), Bazılkan (2005: 63-118), Berta (2010: 127-189), Karcubay (2012: 165-237), Ercilasun (2016: 499-629) ve Aydın (2017: 47-119) e harfli transkripsiyonu tercih etmişlerdir. Abdurrahmanov-Rüstemov 
(1982: 101-114) ve Recebov-Memmedov (1993: 70-153) ise ə ile transkribe etmişlerdir. IPA alfabesinde yarı açık ön düz ünlü için $\varepsilon$ tavsiye edilmiştir. Bize göre anlam değişikliği yaratan her farklılık bir sestir ve bu durumdaki seslere göre e ve ä şeklinde transkribe edilmelidir.

\section{2. “»” nasıl transkribe edilmiştir?}

$\uparrow$ harfini kalın ünlü olarak belirtmek için eserlerini kiril alfabesiyle hazırlayan Radlov (1895: 5-83), Melioransky (1899: 60-79), Malov (1951: 27-70), Aydarov (1971: 286334), Abdurrahmanov-Rüstemov (1982: 101-114), Recebov-Memmedov (1993: 70-153), Sıdıkov-Konkobaev (2001: 54-95), Sadıkov (2004: 76-120) harfi ы olarak transkribe etmişlerdir. Gabain (1950: 247-258), Tekin (1968: 229-253), Amanjalov (2003: 154-180), Bazılkan (2005: 63-118) ve Berta (2010: 127-189)'da ï şeklindedir. Ï Fransızca ve Flamenkçe'de i harfinin okunuşunu düzeltmek için kullanılır. Mesela Fr. Maïs "mısır" mais "fakat". Thomsen (1896: 97-133) ve Karcubay (2012: 165-237) y şeklini tercih ederken Vambery (1898: 26-85) farklı olarak i şeklinde transkribe etmiştir. Y Türkmence ve Lehçede düz kapalı arka ünlü ses için kullanılmaktadır. Ancak y işareti genel dünya dillerinde ünsüz bir sesi göstermek için kullanıldığı unutulmamalıdır. I şeklinin ${ }^{\mathbf{0}} \mathrm{kısmı,} \mathrm{ağız} \mathrm{araş-}$ tırmalarında yuvarlaklaşmayı göstermek için kullanılmaktadır. Orkun (1936: 22-121), Tekin (1968: 229-253) (1968 basımlı kitabı hariç), Ergin (2008: 2-81), Şükürov (1993: 218-268), Xudiyev, Ercilasun (2016: 499-629) ve Aydın (2017: 47-119) ı şeklinde transkribe etmiştir. IPA alfabesinde kapalı arka düz ünlü için $\mathbf{w}$ tavsiye edilmiştir. Görüldüğü üzere 5 varyant meydana gelmiştir. Biz o ve u harfinin durumunu ve “ şeklinin ince sesleri belirtmek için kullanılmasını gözeterek $\mathbf{1}$ şeklinde transkribe edilmesinden yanayız.

$\uparrow$ harfini ince ünlü olarak belirtmek için Radlov (1895: 5-83), Thomsen (1896: 97133), Vambery (1898: 26-85), Melioransky (1899: 60-79), Orkun (1936: 22-121), Gabain (1950: 247-258), Malov (1951: 27-70), Tekin (1968: 229-253), Ergin (2008: 2-81), Aydarov (1971: 286-334), Şükürov (1993: 218-268), Amanjalov (2003: 154-180), Bazılkan (2005: 63-118), Geng (2005: 94-223), Berta (2010: 127-189), Karcubay (2012: 165-237), Hudiyev (2015: 188-237), Ercilasun (2016: 499-629) ve Aydın (2017: 47-119) eserlerinde i şeklinde transkribe etmişlerdir. Abdurrahmanov-Rüstemov (1982: 101-114), Recebov-Memmedov (1993: 70-153), Sıdıkov-Konkobaev (2001: 54-95) ve Sadıkov (2004: 76-120) eserlerini kiril alfabesiyle yazdıkları için и şeklinde transkribe etmişlerdir. И harfinin Latin alfabesinde karşılığı i sesini vermektedir. IPA alfabesinde kapalı ön düz ünlü için i tavsiye edilmiştir. Biz de gerek Türkologlara gerek ise IPA'ya uyarak i harfiyle transkribe edilmesinden yanayı.

\section{3. > nasıl transkribe edilmiştir?}

$>$ harfini belirtmek için Radlov (1895: 5-83), Melioransky (1899: 60-79), Malov (1951: 27-70), Aydarov (1971: 286-334), Abdurrahmanov-Rüstemov (1982: 101-114), Recebov-Memmedov (1993: 70-153), Sidıkov-Konkobaev (2001: 54-95) ve Sadıkov (2004: 76-120) eserlerini kiril alfabesiyle yazdıkları için $\mathbf{y}$ ve $\mathbf{o}$ harfleriyle transkribe etmişlerdir. $\mathbf{y}$ harfi latin alfabesinde $\mathbf{u}$ harfine karşllk gelmektedir. Thomsen (1896: 97-133), Vambery (1898: 26-85), Orkun (1936: 22-121), Gabain (1950: 247-258), Tekin (1968: 229- 
253), Ergin (2008: 2-81), Şükürov (1993: 218-268), Amanjalov (2003: 154-180), Bazılkan (2005: 63-118), Geng (2005: 94-223), Karcubay (2012: 165-237), Hudiyev (2015: 188237), Ercilasun (2016: 499-629) ve Aydin (2017: 47-119) o ve u harflariyle transkribe etmişlerdir. Berta (2010: 127-189) eserinde o, u ve o-u arası sesi ifade ettiğini belirttiği w harfiyle transkribe etmiştir. IPA alfabesinde açık arka yuvarlak ünlü için $\mathbf{p}$, yarı kapalı arka yuvarlak ünlü için $\mathbf{0}$, kapalı arka yuvarlak ünlü için $\mathbf{u}$ tavsiye edilmiştir. Bize göre $\mathbf{0}$ ve $\mathbf{u}$ şeklinde transkribe edilmelidir.

\subsection{N nasıl transkribe edilmiştir?}

$\mathrm{N}$ harfini Radlov (1895: 5-83), Thomsen (1896: 97-133), Vambery (1898: 26-85), Melioransky (1899: 60-79), Orkun (1936: 22-121), Gabain (1950: 247-258), Malov (1951: 27-70), Tekin (1968: 229-253), Ergin (2008: 2-81), Abdurrahmanov-Rüstemov (1982: 101-114), Şükürov (1993: 218-268), Amanjalov (2003: 154-180), Sadıkov (2004: 76-120), Bazllkan (2005: 63-118), Geng (2005: 94-223), Berta (2010: 127-189), Karcubay (2012: 165-237), Hudiyev (2015: 188-237), Ercilasun (2016: 499-629) ve Aydın (2017: 47-119) açı ön yuvarlak ünlüyü belirtmek için ö harfini; Aydarov (1971: 286-334), RecebovMemmedov (1993: 70-153) ve Sıdıkov-Konkobaev (2001: 54-95) /ө/ harfini kullanmışlardır. Kapalı ön yuvarlak ünlüyü belirtmek için Radlov (1895: 5-83), Melioransky (1899: 60-79) ve Malov (1951: 27-70) $\ddot{y}$ harfiyle; Thomsen (1896: 97-133), Vambery (1898: 2685), Orkun (1936: 22-121), Gabain (1950: 247-258), Tekin (1968: 229-253), Ergin (2008: 2-81), Şükürov (1993: 218-268), Amanjalov (2003: 154-180), Bazılkan (2005: 63-118), Karcubay (2012: 165-237), Xudiyev, Ercilasun (2016: 499-629) ve Aydın (2017: 47-119) ü harfiyle; Aydarov (1971: 286-334), Abdurrahmanov-Rüstemov (1982: 101-114), Recebov-Memmedov (1993: 70-153), Sıdıkov-Konkobaev (2001: 54-95) ve Sadıkov (2004: 76-120) Y harfiyle transkribe etmişlerdir. Berta (2010: 127-189) ise $\mathbf{N}$ harfini ö, ü ve ö-ü arası sesi belirtmek için kullandığı $\ddot{\mathbf{w}}$ harfiyle transkribe etmiştir. IPA, açık ön yuvarlak ünlü için $\mathbf{E}$ harfini, kapalı ön yuvarlak ünlü için y harfini tavsiye etmiştir. Bize göre“ işaretinin sesleri öne yaklaştırdığı göz önünde bulundurularak ö ve ü şeklinde transkribe edilmelidir. Berta (2010: 127-189)'nın belirttiği ö-ü arası ses için de IPA alfabesinde “kapalıya yakın öne yakın yuvarlak ünlü" için tavsiye edilen $\mathbf{Y}$ harfiyle transkribe edilmelidir.

\section{Kalın Ünlülerle Ve İnce Ünlülerle Kullanılan Ünsüzlerin Transkripsi- yonu}

Kalın ünlülerle ve ince ünlülerle kullanılan ünsüzler nasıl transkribe edilmiş ve nasıl

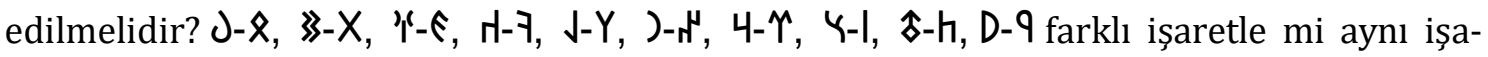
retle mi transkribe edilmeli? Sorusuna cevap aranmış, Türkologların yorumları incelenmiş ve yeni teklifler sunulmuştur.

Eserlerini kiril alfabesiyle hazırlayan Radlov (1895: 5-83), Melioransky (1899: 6079), Malov (1951: 27-70), Aydarov (1971: 286-334), Abdurrahmanov-Rüstemov (1982: 101-114), Recebov-Memmedov (1993: 70-153), Sıdıkov-Konkobaev (2001: 54-95), Sadıkov (2004: 76-120) $\mathrm{J}$ harfini belirtmek $\boldsymbol{\sigma}$ olarak transkribe etmişlerdir. Eserlerini latin alfabesiyle hazırlayan Thomsen (1896: 97-133), Vambery (1898: 26-85), Orkun (1936: 22-121), Gabain (1950: 247-258), Tekin (1968: 229-253), Ergin (2008: 2-81), Şükürov (1993: 218-268), Amanjalov (2003: 154-180), Bazılkan (2005: 63-118), Geng (2005: 94- 
223), Berta (2010: 127-189), Karcubay (2012: 165-237), Xudiyev, Ercilasun (2016: 499629) ve Aydın (2017: 47-119) b olarak transkribe etmişlerdir. Aynı şekilde eserlerini kiril alfabesiyle hazırlayan Radlov (1895: 5-83), Melioransky (1899: 60-79), Malov (1951: 2770), Aydarov (1971: 286-334), Abdurrahmanov-Rüstemov (1982: 101-114), RecebovMemmedov (1993: 70-153), Sidıkov-Konkobaev (2001: 54-95), Sadıkov (2004: 76-120) § harfini $\boldsymbol{\sigma}$ olarak transkribe etmiştir. Eserlerini latin alfabesiyle hazırlayan Thomsen (1896: 97-133), Vambery (1898: 26-85), Orkun (1936: 22-121), Gabain (1950: 247-258), Tekin (1968: 229-253), Ergin (2008: 2-81), Şükürov (1993: 218-268), Amanjalov (2003: 154180), Bazllkan (2005: 63-118), Berta (2010: 127-189), Karcubay (2012: 165-237), Xudiyev, Ercilasun (2016: 499-629) ve Aydın (2017: 47-119) b olarak transkribe etmişlerdir. Ancak kalın ünlüler yanında kullanılan $\partial$ ve ince ünlüler yanında kullanılan $\widehat{\gamma}$ harflerinin transkribi farklı olmalıdır. Ön ünlüler ünsüzleri içpatlamalı hale getireceği için $\widehat{\boldsymbol{\chi}}$ harfini IPA alfabesindeki çiftdudaksıl içpatlamalı ünsüz $\mathbf{b}$ ile $\circlearrowright$ harfini ise ötümlü çiftdudaksıl patlamalı ünsüz b ile transkribe edebiliriz.

Eserlerini kiril alfabesiyle hazırlayan Radlov (1895: 5-83), Melioransky (1899: 6079), Malov (1951: 27-70), Aydarov (1971: 286-334), Abdurrahmanov-Rüstemov (1982: 101-114), Recebov-Memmedov (1993: 70-153), Sıdıkov-Konkobaev (2001: 54-95), Sadıkov (2004: 76-120) 》 harfini belirtmek д olarak transkribe etmişlerdir. Eserlerini latin alfabesiyle hazırlayan Thomsen (1896: 97-133), Vambery (1898: 26-85), Orkun (1936: 22-121), Gabain (1950: 247-258), Tekin (1968: 229-253), Ergin (2008: 2-81), Şükürov (1993: 218-268), Amanjalov (2003: 154-180), Bazllkan (2005: 63-118), Geng (2005: 94223), Berta (2010: 127-189), Karcubay (2012: 165-237), Xudiyev, Ercilasun (2016: 499629) ve Aydın (2017: 47-119) d olarak transkribe etmişlerdir. Aynı şekilde eserlerini kiril alfabesiyle hazırlayan Radlov (1895: 5-83), Melioransky (1899: 60-79), Malov (1951: 2770), Aydarov (1971: 286-334), Abdurrahmanov-Rüstemov (1982: 101-114), RecebovMemmedov (1993: 70-153), Sidıkov-Konkobaev (2001: 54-95), Sadıkov (2004: 76-120) X harfini belirtmek д olarak transkribe etmişlerdir. Eserlerini latin alfabesiyle hazırlayan Thomsen (1896: 97-133), Vambery (1898: 26-85), Orkun (1936: 22-121), Gabain (1950: 247-258), Tekin (1968: 229-253), Ergin (2008: 2-81), Şükürov (1993: 218-268), Amanjalov (2003: 154-180), Bazılkan (2005: 63-118), Karcubay (2012: 165-237), Xudiyev, Ercilasun (2016: 499-629) ve Aydın (2017: 47-119) d olarak transkribe etmişlerdir. Bu isimlerden farklı olarak Berta (2010: 127-189) d harfini $\boldsymbol{\delta}$ olarak transkribe etmiştir. 》 harfi için kalın ünlüler yanında IPA alfabesinde de tavsiye edilen ötümlü dişyuvasal patlamalı ünsüzü belirten d kullanılabilir. IPA alfabesinde ötümlü üstdamaksıl patlamalı ünsüz ses için $\mathbf{d}$ tavsiye edilmiştir. Greek alfabesinde delta olarak tanımlanan $\boldsymbol{\delta}$ harfi ötümlü üstdamaksıl patlamalı ses ürettiği için ince ünlüler yanında kullanılabilir.

Eserlerini kiril alfabesiyle hazırlayan Radlov (1895: 5-83), Melioransky (1899: 6079), Malov (1951: 27-70), '1' harfini belirtmek için 5 ile; Aydarov (1971: 286-334), Abdurrahmanov-Rüstemov (1982: 101-114), Recebov-Memmedov (1993: 70-153), Sadıkov (2004: 76-120) ғ ile Sıdıkov-Konkobaev (2001: 54-95) ise $\mathbf{\Gamma}$ olarak transkribe etmişlerdir. Eserlerini latin alfabesiyle hazırlayan Thomsen (1896: 97-133), Gabain (1950: 247-258), Tekin (1968: 229-253) (1968), Amanjalov (2003: 154-180), Bazllkan (2005: 63-118), Berta (2010: 127-189) $\gamma$ ile; Vambery (1898: 26-85), Orkun (1936: 22-121), Tekin (1968: 
229-253) (1968 yllındaki eseri hariç), Ercilasun (2016: 499-629) ve Aydın (2017: 47-119) g ile; Ergin (2008: 2-81) g ile; Geng (2005: 94-223) ve Karcubay (2012: 165-237) y ile Şükürlü ve Xudiyev $\breve{\mathbf{g}}$ ile transkribe etmiștir. Greek alfabesinde kullanılan gamma $\boldsymbol{\gamma}$ kelime başı hariç yanında bir ünsüz ses olmadan kullanılamayacağı için bu transkribe mesafeli durmaktayız. $\mathbf{\gamma}$ konusunda ise IPA alfabesinde ötümlü artdamaksal sürtünmeli ünsüz olarak belirtildiği için çekincemiz vardır. IPA alfabesinde ötümlü küçükdilsil patlamalı ünsüz için $\mathbf{G}$ tavsiye edilmiştir. Bu durumda biz de $\mathbf{g}$ transkribine katılıyoruz.

Eserlerini kiril alfabesiyle hazırlayan Radlov (1895: 5-83), Melioransky (1899: 6079), Malov (1951: 27-70), Aydarov (1971: 286-334), Abdurrahmanov-Rüstemov (1982: 101-114), Sıdıkov-Konkobaev (2001: 54-95), Sadıkov (2004: 76-120) § harfini г RecebovMemmedov (1993: 70-153) ise $\mathbf{\kappa}$ olarak transkribe etmiştir. Eserlerini latin alfabesiyle hazırlayan Thomsen (1896: 97-133), Vambery (1898: 26-85), Orkun (1936: 22-121), Gabain (1950: 247-258), Tekin (1968: 229-253), Ergin (2008: 2-81), Şükürov (1993: 218268), Bazılkan (2005: 63-118), Xudiyev, Ercilasun (2016: 499-629) ve Aydın (2017: 47119) g olarak transkribe etmişlerdir. Geng (2005: 94-223) ve Karcubay (2012: 165-237) g şeklinde Berta (2010: 127-189) ise $\gamma$ olarak transkribe etmiştir. IPA alfabesinde ötümlü artdamaksal patlamalı ünsüz için $\mathbf{g}$ tavsiye edilmiştir. Biz de $\mathfrak{₹}$ harfinin $\mathbf{g}$ olarak transkribe edilmesi gerekliliğine katılıyoruz.

Radlov (1895: 5-83), Vambery (1898: 26-85), Melioransky (1899: 60-79), Gabain (1950: 247-258), Malov (1951: 27-70), Tekin (1968: 229-253) (1968 basımlı eseri hariç), Şükürov (1993: 218-268), Hudiyev (2015: 188-237), Ercilasun (2016: 499-629) ve Aydın (2017: 47-119) K harfini k olarak; Thomsen (1896: 97-133), Tekin (1968: 229-253) (1968), Amanjalov (2003: 154-180), Bazılkan (2005: 63-118), Geng (2005: 94-223), Karcubay (2012: 165-237) q olarak; Aydarov (1971: 286-334), Recebov-Memmedov (1993: 70-153), Sıdıkov-Konkobaev (2001: 54-95), Sadıkov (2004: 76-120) қ olarak; Orkun (1936: 22-121) $\boldsymbol{k}$ şeklinde, Ergin (2008: 2-81) ise $\mathbf{k}$ olarak transkribe etmiştir. IPA alfabesinde ötümsüz küçükdilsil patlamalı ünsüz q olarak tavsiye edilmiştir. Biz de $\mathbf{r}$ harfinin $\mathbf{q}$ şeklinde transkribe edilmesini doğru buluyoruz.

Eserlerini kiril alfabesiyle hazırlayan Radlov (1895: 5-83), Melioransky (1899: 6079), Malov (1951: 27-70), Aydarov (1971: 286-334), Abdurrahmanov-Rüstemov (1982: 101-114), Recebov-Memmedov (1993: 70-153), Sıdıkov-Konkobaev (2001: 54-95), Sadıkov (2004: 76-120) $\exists$ harfini belirtmek к olarak transkribe etmişlerdir. Eserlerini latin alfabesiyle hazırlayan Thomsen (1896: 97-133), Vambery (1898: 26-85), Orkun (1936: 22-121), Gabain (1950: 247-258), Tekin (1968: 229-253), Ergin (2008: 2-81), Şükürov (1993: 218-268), Amanjalov (2003: 154-180), Bazılkan (2005: 63-118), Geng (2005: 94223), Berta (2010: 127-189), Karcubay (2012: 165-237), Xudiyev, Ercilasun (2016: 499629) ve Aydın (2017: 47-119) k olarak transkribe etmişlerdir. IPA alfabesinde ötümsüz artdamaksal patlamalı ünsüz $\mathbf{k}$ olarak tavsiye edilmiştir. Biz de 7 harfinin $\mathbf{k}$ şeklinde transkribe edilmesini doğru buluyoruz.

Eserlerini kiril alfabesiyle hazırlayan Radlov (1895: 5-83), Melioransky (1899: 6079), Malov (1951: 27-70), Aydarov (1971: 286-334), Abdurrahmanov-Rüstemov (1982: 101-114), Recebov-Memmedov (1993: 70-153), Sıdıkov-Konkobaev (2001: 54-95), Sadı- 
kov (2004: 76-120) $\mathrm{J}$ harfini belirtmek л olarak transkribe etmişlerdir. Eserlerini latin alfabesiyle hazırlayan Vambery (1898: 26-85), Orkun (1936: 22-121), Gabain (1950: 247258), Tekin (1968: 229-253), Ergin (2008: 2-81), Şükürov (1993: 218-268), Amanjalov (2003: 154-180), Bazlkan (2005: 63-118), Geng (2005: 94-223), Berta (2010: 127-189), Karcubay (2012: 165-237), Xudiyev, Ercilasun (2016: 499-629) ve Aydın (2017: 47-119) I olarak Thomsen (1896: 97-133) ise $\mathbf{l}$ olarak transkribe etmişlerdir. IPA alfabesinde dişyuvasal yansürtünmesiz ünsüz olarak $\mathbf{l}$ tavsiye edilmiștir. Biz de $\mathbf{V}$ harfinin $\mathbf{l}$ şeklinde transkribe edilmesini doğru buluyoruz. Bununla birlikte l harfini Aydarov (1971: 286-334), Abdurrahmanov-Rüstemov (1982: 101-114), Recebov-Memmedov (1993: 70-153), SidıkovKonkobaev (2001: 54-95) ve Sadıkov (2004: 76-120) л olarak, Radlov (1895: 5-83), Thomsen (1896: 97-133), Vambery (1898: 26-85), Melioransky (1899: 60-79), Orkun (1936: 22-121), Gabain (1950: 247-258), Malov (1951: 27-70), Tekin (1968: 229-253), Ergin (2008: 2-81), Şükürov (1993: 218-268), Amanjalov (2003: 154-180), , Bazılkan (2005: 63-118), Geng (2005: 94-223), Berta (2010: 127-189), Karcubay (2012: 165-237), Hudiyev (2015: 188-237), Ercilasun (2016: 499-629) ve Aydın (2017: 47-119) l olarak transkribe etmişlerdir. Görüldüğü üzere $J-Y$ ayrımımı sadece Thomsen (1896: 97-133) yapmıștır. IPA alfabesinde artdamaksıllaşmış dişyuvasıl yansürtünmesiz ünsüz olarak $\mathbf{t}$

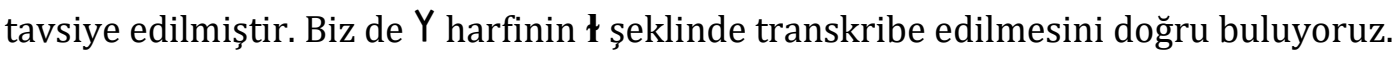

Eserlerini kiril alfabesiyle hazırlayan Radlov (1895: 5-83), Melioransky (1899: 6079), Malov (1951: 27-70), Aydarov (1971: 286-334), Abdurrahmanov-Rüstemov (1982: 101-114), Recebov-Memmedov (1993: 70-153), Sıdıkov-Konkobaev (2001: 54-95), Sadıkov (2004: 76-120) N harfini belirtmek H olarak transkribe etmişlerdir. Eserlerini latin alfabesiyle hazırlayan Thomsen (1896: 97-133), Vambery (1898: 26-85), Orkun (1936: 22-121), Gabain (1950: 247-258), Tekin (1968: 229-253), Ergin (2008: 2-81), Şükürov (1993: 218-268), Amanjalov (2003: 154-180), Bazllkan (2005: 63-118), Geng (2005: 94223), Berta (2010: 127-189), Karcubay (2012: 165-237), Xudiyev, Ercilasun (2016: 499629) ve Aydın (2017: 47-119) $\mathbf{n}$ olarak transkribe etmişlerdir. Diğer taraftan Radlov (1895: 5-83), Melioransky (1899: 60-79), Malov (1951: 27-70), Aydarov (1971: 286-334), Abdurrahmanov-Rüstemov (1982: 101-114), Recebov-Memmedov (1993: 70-153), Sidıkov-Konkobaev (2001: 54-95), Sadıkov (2004: 76-120) N harfini $\mathbf{H}$ olarak transkribe etmiş; Thomsen (1896: 97-133), Vambery (1898: 26-85), Orkun (1936: 22-121), Gabain (1950: 247-258), Tekin (1968: 229-253), Ergin (2008: 2-81), Şükürov (1993: 218-268), Amanjalov (2003: 154-180), Bazllkan (2005: 63-118), Geng (2005: 94-223), Berta (2010: 127-189), Karcubay (2012: 165-237), Xudiyev, Ercilasun (2016: 499-629) ve Aydın (2017: 47-119) n olarak transkribe etmişlerdir. IPA alfabesinde dişyuvasal genizsil ünsüz için n harfini, üstdamaksıl genizsil ünsüz için $\mathbf{\eta}$ harfini tavsiye edilmiştir. Biz de ) harfinin $\mathbf{n}$ şeklinde, $\mathrm{n}^{\mathbf{H}}$ harfinin ise $\mathbf{\eta}$ şeklinde transkribe edilmesinden yanayız.

Eserlerini kiril alfabesiyle hazırlayan Radlov (1895: 5-83), Melioransky (1899: 6079), Malov (1951: 27-70), Aydarov (1971: 286-334), Abdurrahmanov-Rüstemov (1982: 101-114), Recebov-Memmedov (1993: 70-153), Sıdıkov-Konkobaev (2001: 54-95), Sadıkov (2004: 76-120) 4 harfini belirtmek p olarak transkribe etmişlerdir. Eserlerini latin alfabesiyle hazırlayan Thomsen (1896: 97-133), Vambery (1898: 26-85), Orkun (1936: 22-121), Gabain (1950: 247-258), Tekin (1968: 229-253), Ergin (2008: 2-81), Şükürov 
(1993: 218-268), Amanjalov (2003: 154-180), Bazllkan (2005: 63-118), Geng (2005: 94223), Berta (2010: 127-189), Karcubay (2012: 165-237), Xudiyev, Ercilasun (2016: 499629) ve Aydın (2017: 47-119) r olarak transkribe etmişlerdir. İnce ünsüzler yanında kullanılan $\uparrow$ harfini Radlov (1895: 5-83), Melioransky (1899: 60-79), Malov (1951: 27-70), Aydarov (1971: 286-334), Abdurrahmanov-Rüstemov (1982: 101-114), RecebovMemmedov (1993: 70-153), Sidıkov-Konkobaev (2001: 54-95), Sadıkov (2004: 76-120) p olarak transkribe etmiş; Thomsen (1896: 97-133), Vambery (1898: 26-85), Orkun (1936: 22-121), Gabain (1950: 247-258), Tekin (1968: 229-253), Ergin (2008: 2-81), Şükürov (1993: 218-268), Amanjalov (2003: 154-180), Bazılkan (2005: 63-118), Geng (2005: 94223), Berta (2010: 127-189), Karcubay (2012: 165-237), Xudiyev, Ercilasun (2016: 499629) ve Aydın (2017: 47-119) ise $\mathbf{r}$ olarak transkribe etmişlerdir. IPA alfabesinde dişyuvasal titrek ünsüz için $\mathbf{r}$ harfi tavsiye edilmiştir. Ancak üstdamaksıl veya öndamaksıl titrek ünsüz tavsiye edilmemiștir. Bu durumda 4 harfinin $\mathbf{r}$ șeklinde, $\uparrow$ harfinin ise ince ünlülerle kullanımını belirtmek için $\dot{\mathbf{r}}$ olarak transkribe edebiliriz.

Eserlerini kiril alfabesiyle hazırlayan Radlov (1895: 5-83), Melioransky (1899: 6079), Malov (1951: 27-70), Aydarov (1971: 286-334), Abdurrahmanov-Rüstemov (1982: 101-114), Recebov-Memmedov (1993: 70-153), Sidıkov-Konkobaev (2001: 54-95), Sadıkov (2004: 76-120) $\$ harfini belirtmek c olarak transkribe etmişlerdir. Eserlerini latin alfabesiyle hazırlayan Thomsen (1896: 97-133), Vambery (1898: 26-85), Orkun (1936: 22-121), Gabain (1950: 247-258), Tekin (1968: 229-253), Ergin (2008: 2-81), Şükürov (1993: 218-268), Amanjalov (2003: 154-180), Bazılkan (2005: 63-118), Geng (2005: 94223), Berta (2010: 127-189), Karcubay (2012: 165-237), Xudiyev, Ercilasun (2016: 499629) ve Aydın (2017: 47-119) s olarak transkribe etmişlerdir. İnce ünsüzler yanında kullanılan I harfini Radlov (1895: 5-83), Melioransky (1899: 60-79), Malov (1951: 27-70), Aydarov (1971: 286-334), Abdurrahmanov-Rüstemov (1982: 101-114), RecebovMemmedov (1993: 70-153), Sidıkov-Konkobaev (2001: 54-95), Sadıkov (2004: 76-120) c olarak transkribe etmiş; Thomsen (1896: 97-133), Vambery (1898: 26-85), Orkun (1936: 22-121), Gabain (1950: 247-258), Tekin (1968: 229-253), Ergin (2008: 2-81), Şükürov (1993: 218-268), Amanjalov (2003: 154-180), Bazlkan (2005: 63-118), Geng (2005: 94223), Berta (2010: 127-189), Karcubay (2012: 165-237), Xudiyev, Ercilasun (2016: 499629) ve Aydın (2017: 47-119) ise s olarak transkribe etmişlerdir. IPA alfabesinde ötümsüz dişyuvasal sürtünmeli ünsüz için $\mathbf{s}$ harfi tavsiye edilmiştir. Biz ince ünlüler yanında $s$ için s harfini, kalın ünlüler yanında Y işareti için ș harfini teklif etmekteyiz.

Eserlerini kiril alfabesiyle hazırlayan Radlov (1895: 5-83), Melioransky (1899: 6079), Malov (1951: 27-70), Aydarov (1971: 286-334), Abdurrahmanov-Rüstemov (1982: 101-114), Recebov-Memmedov (1993: 70-153), Sıdıkov-Konkobaev (2001: 54-95), Sadıkov (2004: 76-120) $\delta$ harfini belirtmek T olarak transkribe etmişlerdir. Eserlerini latin alfabesiyle hazırlayan Thomsen (1896: 97-133), Vambery (1898: 26-85), Orkun (1936: 22-121), Gabain (1950: 247-258), Tekin (1968: 229-253), Ergin (2008: 2-81), Şükürov (1993: 218-268), Amanjalov (2003: 154-180), Bazlkan (2005: 63-118), Geng (2005: 94223), Berta (2010: 127-189), Karcubay (2012: 165-237), Xudiyev, Ercilasun (2016: 499629) ve Aydın (2017: 47-119) t olarak transkribe etmişlerdir. İnce ünsüzler yanında kullanılan h harfini Radlov (1895: 5-83), Melioransky (1899: 60-79), Malov (1951: 27-70), 
Aydarov (1971: 286-334), Abdurrahmanov-Rüstemov (1982: 101-114), RecebovMemmedov (1993: 70-153), Sidıkov-Konkobaev (2001: 54-95), Sadıkov (2004: 76-120) t olarak transkribe etmiş; Thomsen (1896: 97-133), Vambery (1898: 26-85), Orkun (1936: 22-121), Gabain (1950: 247-258), Tekin (1968: 229-253), Ergin (2008: 2-81), Şükürov (1993: 218-268), Amanjalov (2003: 154-180), Bazılkan (2005: 63-118), Geng (2005: 94223), Berta (2010: 127-189), Karcubay (2012: 165-237), Xudiyev, Ercilasun (2016: 499629) ve Aydın (2017: 47-119) ise t olarak transkribe etmişlerdir. \$ için $\mathbf{t}$ işaretini, $\mathbf{h}$ için ise $\mathbf{t}$ işaretini tavsiye edebiliriz.

Eserlerini kiril alfabesiyle hazırlayan Aydarov (1971: 286-334), AbdurrahmanovRüstemov (1982: 101-114), Sıdıkov-Konkobaev (2001: 54-95), Sadıkov (2004: 76-120) Y harfini belirtmek й olarak transkribe etmişlerdir. Radlov (1895: 5-83), Melioransky (1899: 60-79), Malov (1951: 27-70), Recebov-Memmedov (1993: 70-153) ise j olarak transkribe etmişlerdir. Eserlerini latin alfabesiyle hazırlayan Thomsen (1896: 97-133), Vambery (1898: 26-85), Amanjalov (2003: 154-180), Karcubay (2012: 165-237) j olarak transkribe ederken Orkun (1936: 22-121), Gabain (1950: 247-258), Tekin (1968: 229-253), Ergin (2008: 2-81), Şükürov (1993: 218-268), Bazılkan (2005: 63-118), Geng (2005: 94-223), Berta (2010: 127-189), Xudiyev, Ercilasun (2016: 499-629) ve Aydın (2017: 47-119) y olarak transkribe etmişlerdir. Yazarlar ince seslerle kullanılan y harfi transkribinde de farklılığa gitmemişler ve sırasıyla yukarıdaki gibi $\mathbf{\mathbf { n }} \mathbf{j}, \mathbf{j}, \mathbf{j}, \mathbf{y}$ olarak transkribe etmişlerdir. IPA alfabesinde damaksıl sürtünmesiz ünsüz $\mathbf{j}$ tavsiye edilmiştir. Yine aynı şekilde öndamaksıl yansürtünmesiz ünsüz için $\boldsymbol{\Lambda}$ tavsiye edilmiştir. Bu durumda $D$ için $\mathbf{j}$ transkribini 9 için y transkribini uygun görüyoruz.

\section{Nötr Ünsüzlerin Transkripsiyonu}

Nötr ünsüzlerin transkripsiyonunda ne tür farklılıklar var sorusuna cevap aranmış ve teklifler sunulmuştur.

Eserlerini kiril alfabesiyle hazırlayan Radlov (1895: 5-83), Melioransky (1899: 6079), Malov (1951: 27-70), Aydarov (1971: 286-334), Abdurrahmanov-Rüstemov (1982: 101-114), Recebov-Memmedov (1993: 70-153), Sıdıkov-Konkobaev (2001: 54-95), Sadıkov (2004: 76-120) ç harfini belirtmek $\mathbf{ч}$ olarak transkribe etmişlerdir. Eserlerini latin alfabesiyle hazırlayan Thomsen (1896: 97-133), Vambery (1898: 26-85), Orkun (1936: 22-121), Gabain (1950: 247-258), Tekin (1968: 229-253), Ergin (2008: 2-81), Amanjalov (2003: 154-180), Bazlkan (2005: 63-118), Geng (2005: 94-223), Berta (2010: 127-189), Karcubay (2012: 165-237) č ile Şükürov (1993: 218-268), Xudiyev, Ercilasun (2016: 499629) ve Aydın (2017: 47-119) ç olarak transkribe etmişlerdir. IPA alfabesinde ötümsüz damaksıl sürtünmeli ünsüz için ç tavsiye edilmiştir. Biz de buna katılıyoruz.

Eserlerini kiril alfabesiyle hazırlayan Radlov (1895: 5-83), Melioransky (1899: 6079), Malov (1951: 27-70), Aydarov (1971: 286-334), Abdurrahmanov-Rüstemov (1982: 101-114), Recebov-Memmedov (1993: 70-153), Sidıkov-Konkobaev (2001: 54-95), Sadıkov (2004: 76-120) $\gg$ harfini belirtmek M olarak transkribe etmişlerdir. Eserlerini latin alfabesiyle hazırlayan Thomsen (1896: 97-133), Vambery (1898: 26-85), Orkun (1936: 22-121), Gabain (1950: 247-258), Tekin (1968: 229-253), Ergin (2008: 2-81), Şükürov (1993: 218-268), Amanjalov (2003: 154-180), Bazılkan (2005: 63-118), Geng (2005: 94223), Berta (2010: 127-189), Karcubay (2012: 165-237), Xudiyev, Ercilasun (2016: 499- 
629) ve Aydın (2017: 47-119) m olarak transkribe etmişlerdir. IPA alfabesinde ötümsüz damaksıl sürtünmeli ünsüz için $\mathbf{m}$ tavsiye edilmiştir. Biz de $\gg$ harfinin $\mathbf{m}$ ile transkribe edilmesini doğru buluyoruz.

Eserlerini kiril alfabesiyle hazırlayan Radlov (1895: 5-83), Melioransky (1899: 6079), Malov (1951: 27-70), Aydarov (1971: 286-334), Recebov-Memmedov (1993: 70-153), Sıdıkov-Konkobaev (2001: 54-95) † ligatürünü н ile, Abdurrahmanov-Rüstemov (1982: 101-114) нत्रile, Sadıkov (2004: 76-120) ise нг şeklinde transkribe etmiştir. Eserlerini latin alfabesiyle hazırlayan Gabain (1950: 247-258), Tekin (1968: 229-253) (1968), Amanjalov (2003: 154-180), Bazllkan (2005: 63-118), Geng (2005: 94-223), Karcubay (2012: 165-237), Xudiyev, Ercilasun (2016: 499-629) ve Aydın (2017: 47-119) y ile, Vambery (1898: 26-85), Tekin (1968: 229-253) (1968 eseri hariç) ve Berta (2010: 127-189) ñ ile, Thomsen (1896: 97-133) ǹ ile, Orkun (1936: 22-121) n ile, Ergin (2008: 2-81) ñ ile, Şükürov (1993: 218-268) $\boldsymbol{n}$ ile, Amanjalov (2003: 154-180) $\boldsymbol{\eta}$ ile transkribe etmiştir. IPA alfabesinde Artdamaksıl genizsil ünsüz için $\mathbf{y}$ tavsiye edilmiştir. Biz de $\mathbf{\eta}$ şeklinde transkriptin doğru olduğunu düşünüyoruz.

3 ligatürünü Radlov (1895: 5-83) ve Vambery (1898: 26-85) bazen i bazen j ile; Thomsen (1896: 97-133) ve Melioransky (1899: 60-79) i ile; Abdurrahmanov-Rüstemov (1982: 101-114) ve Sadıkov (2004: 76-120) нй ile; Tekin (1968: 229-253), Berta (2010: 127-189) ve Ercilasun (2016: 499-629) ń ile; Amanjalov (2003: 154-180), Geng (2005: 94-223) ve Aydın (2017: 47-119) ñ ile; Orkun (1936: 22-121) y ile; Gabain (1950: 247258) ny ile; Malov (1951: 27-70) $\tilde{\mathbf{H}}$ ile; Ergin (2008: 2-81) ny ile; Aydarov (1971: 286-334) bazen н bazen й ile; Şükürov (1993: 218-268) bazen n bazen ñ ile; Recebov-Memmedov (1993: 70-153) j̃ ile; Sıdıkov-Konkobaev (2001: 54-95) bazen н bazen н ile; Bazılkan (2005: 63-118) ň ile; Karcubay (2012: 165-237) bazen j bazen $\eta$ ile; Hudiyev (2015: 188-237) bazen n bazen $\eta$ ile transkribe etmiştir. Görüldügü gibi 16 varyant bulunmaktadır. Bunun sebebi günümüz Türk dillerinde bu sesi barındıran kelime sayısının sınırlı olmasındandır. IPA alfabesinde damaksıl genizsil ünsüz için $\mathbf{~}$ tavsiye edilmiştir. Bunun yanı sıra damaksıllşma için $\mathbf{j}$ tavsiye edilmiştir. Biz de $\mathbf{n}^{\mathbf{j}}$ veya $\mathbf{n}$ şeklinde transkripti doğru buluyoruz.

Eserlerini kiril alfabesiyle hazırlayan Radlov (1895: 5-83), Melioransky (1899: 6079), Malov (1951: 27-70), Aydarov (1971: 286-334), Abdurrahmanov-Rüstemov (1982: 101-114), Recebov-Memmedov (1993: 70-153), Sıdıkov-Konkobaev (2001: 54-95), Sadıkov (2004: 76-120) 1 harfini belirtmek II olarak transkribe etmişlerdir. Eserlerini latin alfabesiyle hazırlayan Thomsen (1896: 97-133), Vambery (1898: 26-85), Orkun (1936: 22-121), Gabain (1950: 247-258), Tekin (1968: 229-253), Ergin (2008: 2-81), Şükürov (1993: 218-268), Amanjalov (2003: 154-180), Bazılkan (2005: 63-118), Geng (2005: 94223), Berta (2010: 127-189), Karcubay (2012: 165-237), Xudiyev (2015: 188-237), Ercilasun (2016: 499-629) ve Aydın (2017: 47-119) p olarak transkribe etmişlerdir. IPA alfabesinde ötümsüz çiftdudaksal patlamalı ünsüz için $\mathbf{p}$ tavsiye edilmiştir. Biz de 1 harfinin $\mathbf{p}$ ile transkribe edilmesini doğru buluyoruz.

Eserlerini kiril alfabesiyle hazırlayan Radlov (1895: 5-83), Melioransky (1899: 6079), Malov (1951: 27-70), Aydarov (1971: 286-334), Abdurrahmanov-Rüstemov (1982: 101-114), Recebov-Memmedov (1993: 70-153), Sidıkov-Konkobaev (2001: 54-95), Sadı- 
kov (2004: 76-120) $¥$ harfini belirtmek III olarak transkribe etmişlerdir. eserlerini latin alfabesiyle hazırlayan Thomsen (1896: 97-133), Vambery (1898: 26-85), Gabain (1950: 247-258), Tekin (1968: 229-253) (1968), Amanjalov (2003: 154-180), Bazılkan (2005: 63118), Geng (2005: 94-223), Berta (2010: 127-189), Karcubay (2012: 165-237) š ile; Orkun (1936: 22-121), Tekin (1968: 229-253) (1968 basıml eseri hariç), Ergin (2008: 2-81), Şükürov (1993: 218-268), Xudiyev (2015: 188-237), Ercilasun (2016: 499-629) ve Aydın (2017: 47-119) \$̧ olarak transkribe etmişlerdir. IPA alfabesinde ötümsüz artdişyuvasal sürtünmeli ünsüz için $\int$ tavsiye edilmiştir. Biz Ç harfi için kabul ettiğimiz ç harfindeki sürtünme eğiliminin harf altındaki kuyruk kaynaklı olması sebebiyle Ş harfinin ş ile transkribe edilmesini doğru buluyoruz.

Eserlerini kiril alfabesiyle hazırlayan Radlov (1895: 5-83), Melioransky (1899: 6079), Malov (1951: 27-70), Aydarov (1971: 286-334), Abdurrahmanov-Rüstemov (1982: 101-114), Recebov-Memmedov (1993: 70-153), Sıdıkov-Konkobaev (2001: 54-95), Sadıkov (2004: 76-120) $4 \mathrm{t}$ harfini belirtmek 3 olarak transkribe etmişlerdir. eserlerini latin alfabesiyle hazırlayan Thomsen (1896: 97-133), Vambery (1898: 26-85), Orkun (1936: 22-121), Gabain (1950: 247-258), Tekin (1968: 229-253), Ergin (2008: 2-81), Şükürov (1993: 218-268), Amanjalov (2003: 154-180), Bazlkan (2005: 63-118), Geng (2005: 94223), Berta (2010: 127-189), Karcubay (2012: 165-237), Xudiyev (2015: 188-237), Ercilasun (2016: 499-629) ve Aydın (2017: 47-119) z olarak transkribe etmişlerdir. IPA alfabesinde ötümlü dişyuvasal sürtünmeli ünsüz için $\mathbf{z}$ tavsiye edilmiştir. Biz de 4 h harfinin $\mathbf{z}$ ile transkribe edilmesini doğru buluyoruz.

\section{4. Ünlü-Ünsüz veya Ünsüz-Ünlü Değerinde Olan İşaretlerin Transkripsi- yonu}

Ünlü-ünsüz veya ünsüz-ünlü değerinde olan $\downarrow, F-B, \triangleleft, \Psi$ harflere ait $V+K K+V$ yapıları ayrı ayrı işaretlerle mi tek işaretle mi transkribe edilmiş sorusuna cevap aranmış ve yeni önerilerde bulunulmuştur.

$\downarrow$ Harfi iki sesi barındıran bir işarettir. Ancak transkripsiyonunda iki sesin birlikteliği gösterilmesi bir gerekliliktir. Thomsen (1896: 97-133), Melioransky (1899: 60-79), Orkun (1936: 22-121) ve Aydın (2017: 47-119) bu ayrıntıya dikkat etmiștir: Radlov (1895: 5-83) /yk-ky ko-ok/, Thomsen (1896: 97-133) /uq-qu oqqo/, Vambery (1898: 26-85) /uk-ku ko-ok/, Melioransky (1899: 60-79) /yk-ky kook/, Orkun (1936: 22-121) / ${ }^{\mathrm{u}} \mathrm{k}$ - $k \mathrm{u}{ }^{\mathrm{o}} \mathrm{k}-\mathrm{ko}$ /, Gabain (1950: 247-258) /uq-qu qo-oq/, Malov (1951: 27-70) /yk-ky ko-ok/, Tekin (1968: 229-253) /uq qo-oq/, Ergin (2008: 2-81) /ukku ḳo-ok/, Aydarov (1971: 286-334) /уқ-қу қо-оқ/, Abdurrahmanov-Rüstemov (1982: 101-114) /уқ-қу қо-оқ/, Şükürov (1993: 218-268) /uk-ku ko-ok/, Recebov-Memmedov (1993: 70-153) /ук-ку ко-ок/, Sidıkov-Konkobaev (2001: 54-95) /ук-ку ко-ок/, Amanjalov (2003: 154-180) $/{ }^{\mathrm{u}} \mathrm{q}-\mathrm{qu}{ }^{\circ} \mathrm{q}-\mathrm{q} \%$, Sadıkov (2004: 76-120) /уқ-қу қо-оқ/, Bazılkan (2005: 63-118) /uq qo-oq/, Geng (2005: 94-223) /uq-qu qo-oq/, Berta (2010: 127-189) /wq-qu qo-oq/, Karcubay (2012: 165-237) /uq-qu qo-oq/, Xudiyev (2015: 188-237) /uk-

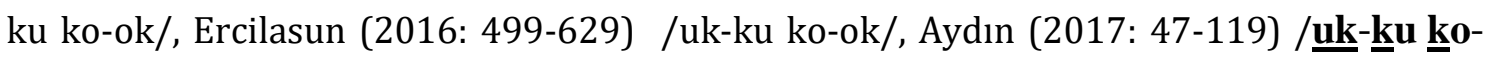
ok$/$. Bize göre /uqq-qu qu-oq/ şeklinde transkribe edilmelidir.

F-B Harfi iki sesi barındıran bir işarettir. Bunun için transkripsiyonunda iki sesin 
birlikteliği gösterilmesi bir gerekliliktir. Thomsen (1896: 97-133), Orkun (1936: 22-121) ve Aydın (2017: 47-119) bu ayrıma dikkat etmiştir: Radlov (1895: 5-83) /кӱ-ӱк к/, Thomsen (1896: 97-133) /kö ük k/, Vambery (1898: 26-85) /uk-ku-ko-ok/, Melioransky (1899: 60-79) /ük-k/, Orkun (1936: 22-121)/"̈k k/, Gabain (1950: 247-258) /kö ük/, Malov (1951: 27-70) /кӧ ӱк к/, Tekin (1968: 229-253) /kö ük/, Ergin (2008: 2-81) /kö ük/, Аydarov (1971: 286-334) /кө үк к/, Abdurrahmanov-Rüstemov (1982: 101-114) /кӧ үк/, Şükürov (1993: 218-268) /kö ük/, Recebov-Memmedov (1993: 70-153) /кө үк/, SıdıkovKonkobaev (2001: 54-95) /кө үк к/, Amanjalov (2003: 154-180) /k̈ ük ök k/, Sadıkov (2004: 76-120) /кӧ үк/, Bazllkan (2005: 63-118) /kö ük ök/, Geng (2005: 94-223) /kö ük kü k/, Berta (2010: 127-189) /kö-ẅk ük-ük/, Karcubay (2012: 165-237) /kö ük/, Xudiyev

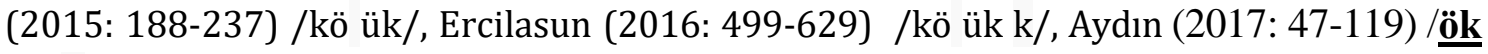
ük k/. Bize göre /ük-kü ök-kö/ş̧eklinde transkribe edilmelidir.

$\triangleleft$ Harfinin transkripsiyonunda Thomsen (1896: 97-133), Melioransky (1899: 6079), Orkun (1936: 22-121) ve Aydın (2017: 47-119) birleștirmeye dikkat etmiştir: Radlov (1895: 5-83) /k-ыk/, Thomsen (1896: 97-133) /q yq-qy/, Vambery (1898: 26-85) /k ik ik/, Melioransky (1899: 60-79) /k ыk-kы/, Orkun (1936: 22-121) / $k^{1} k-k^{1} /$, Gabain (1950: 247-258) /q ïq-qї/, Malov (1951: 27-70) /k ыk-kы/, Tekin (1968: 229-253) /q ïq-qï/, Ergin (2008: 2-81) /k 1k-ḳ1/, Aydarov (1971: 286-334) /қ ық-қы/, AbdurrahmanovRüstemov (1982: 101-114) /қ ық-қы/, Şükürov (1993: 218-268) /k ık-kı/, RecebovMemmedov (1993: 70-153) /к-ык-кы/, Sidıkov-Konkobaev (2001: 54-95) /к ык-кы/, Amanjalov (2003: 154-180) /q ${ }^{i} \mathrm{q}-\mathrm{q}^{\mathrm{i}} /$, Sadıkov (2004: 76-120) /қ ық-қы/, Bazllkan (2005: 63-118) /q ïq-qï/, Geng (2005: 94-223) /q ïq-qï/, Berta (2010: 127-189) /q ïq-qï/, Karcubay (2012: 165-237) /q yq-qy/, Xudiyev (2015: 188-237) /k lk-kl/, Ercilasun (2016: 499629) /k lk-kı/, Aydın (2017: 47-119) / $\underline{\mathbf{k}} \underline{\mathbf{k}}-\underline{\mathbf{k}} \mathbf{l}$. Bize göre $\mathbf{q} \mathbf{q}-\mathbf{q} \mathbf{l}$ şeklinde transkribe edilmelidir.

Y Harfinin transkripsiyonunda Thomsen (1896: 97-133), Orkun (1936: 22-121), Tekin (1968: 229-253) ve Aydın (2017: 47-119) birleştirmeye dikkat etmiştir: Radlov (1895: 5-83) /iq/, Thomsen (1896: 97-133) / ič/ ve /ič/, Orkun (1936: 22-121) / iç/, Malov (1951: 27-70) /ič/, Tekin (1968: 229-253) /iç/, /ič/ ve /iç̧/, Ergin (2008: 2-81) /iç/, Aydarov (1971: 286-334) /іч/, Şükürov (1993: 218-268) iç, Recebov-Memmedov (1993: 70-153) /ич/, Sidıkov-Konkobaev (2001: 54-95) /ич/, Amanjalov (2003: 154-180) /ič/, Sadıkov (2004: 76-120) /ич/, Bazılkan (2005: 63-118) /ič/, Geng (2005: 94-223) /ič/, Berta (2010: 127-189) /iç/, Karcubay (2012: 165-237) /ič/, Xudiyev (2015: 188-237) /iç/, Ercilasun (2016: 499-629) /iç/, Aydın (2017: 47-119) / iç/ şeklinde transkribe etmiştir. Bize göre iç-çi şeklinde transkribe edilmelidir.

\section{Ligatürlerin Transkripsiyonu}

Ligatürler $M 3$ \& birliktelikleri ayrı ayrı mı tek mi transkribe edilmiş sorusuna cevaplar aranmış ve yeni teklifler sunulmuştur.

M Harfinin transkripsiyonunda Thomsen (1896: 97-133), Melioransky (1899: 6079), Orkun (1936: 22-121), Gabain (1950: 247-258), Amanjalov (2003: 154-180) ve Aydın (2017: 47-119) birlikteliğe dikkat etmiştir: Radlov (1895: 5-83) /лт лд/, Thomsen (1896: 
97-133) /łd/, Vambery (1898: 26-85) /ld/, Melioransky (1899: 60-79) /лд/, Orkun (1936: 22-121) /ldd, Gabain (1950: 247-258) /ldd/, Malov (1951: 27-70) /лт лд/, Tekin (1968: 229-253) /lt/, Ergin (2008: 2-81) /ld/, Aydarov (1971: 286-334) /лт лд/, Abdurrahmanov-Rüstemov (1982: 101-114) /лт лд/, Recebov-Memmedov (1993: 70-153) /лт лд/, Şükürov (1993: 218-268) /lt/, Sıdıkov-Konkobaev (2001: 54-95) /лт лд/, Amanjalov (2003: 154-180) /ltt/, Sadıkov (2004: 76-120) /лт лд/, Bazılkan (2005: 63-118) /lt/, Geng (2005: 94-223) /lt/, Berta (2010: 127-189) /ld/, Karcubay (2012: 165-237) /lt ld/, Xudiyev (2015: 188-237) /lt/, Ercilasun (2016: 499-629) /lt/, Aydın (2017: 47-119) /t/. Bize göre lt şeklinde transkribe edilmelidir.

3 Harfinin transkripsiyonunda Thomsen (1896: 97-133), Melioransky (1899: 60-79), Orkun (1936: 22-121), Gabain (1950: 247-258), Amanjalov (2003: 154-180) ve Aydın (2017: 47-119) birlikteliğe dikkat etmiştir: Radlov (1895: 5-83) /нч/, Thomsen (1896: 97-133) /nč/, Vambery (1898: 26-85) /nč/, Melioransky (1899: 60-79) /Hч/, Orkun (1936: 22-121) /nç/, Gabain (1950: 247-258)/nč/, Malov (1951: 27-70) /нч/, Tekin (1968: 229-253) /nč/, Ergin (2008: 2-81) /nç/, Aydarov (1971: 286-334) /нч/, Abdurrahmanov-Rüstemov (1982: 101-114) /нч/, Recebov-Memmedov (1993: 70-153) /нч/, Şükürov (1993: 218-268) /nç/, Sıdıkov-Konkobaev (2001: 54-95) /нч/, Amanjalov (2003:

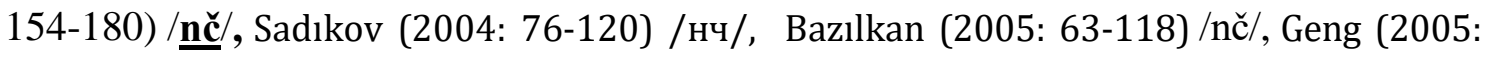
94-223) /nč/, Berta (2010: 127-189) /nc/, Karcubay (2012: 165-237) /nč/, Xudiyev /nç/, Ercilasun (2016: 499-629) nç, Aydın (2017: 47-119) /̧ç/. Bize göre nç şeklinde transkribe edilmelidir.

(:) Harfinin transkripsiyonunda Thomsen (1896: 97-133), Melioransky (1899: 6079), Orkun (1936: 22-121), Gabain (1950: 247-258), Amanjalov (2003: 154-180) ve Aydın (2017: 47-119) birliktelğe dikkat etmiştir: Radlov (1895: 5-83) /нд/, Thomsen (1896: 97133) /nd/, Vambery (1898: 26-85) /nd/, Melioransky (1899: 60-79) /нд/, Orkun (1936: 22-121) /nd/, Gabain (1950: 247-258) /nd/, Malov (1951: 27-70) /HT/, Tekin (1968: 229-253) /nt/, Ergin (2008: 2-81) /nd/, Aydarov (1971: 286-334) /нт/, AbdurrahmanovRüstemov (1982: 101-114) /нт/, Recebov-Memmedov (1993: 70-153) /нт/, Şükürov (1993: 218-268) /nt/, Sidıkov-Konkobaev (2001: 54-95) /нт/, Amanjalov (2003: 154180) /nt/, Sadıkov (2004: 76-120) /нт/, Bazllkan (2005: 63-118) /nt/, Geng (2005: 94223) /nt/, Berta (2010: 127-189) /nd/, Karcubay (2012: 165-237) /nd/, Xudiyev /nt/, Ercilasun (2016: 499-629) /nt/, Aydın (2017: 47-119) /nt/. Bize göre nt șeklinde transkribe edilmelidir.

\section{Yazıtlarda Yazılmayan Ünlülerin Tanskripsiyonu}

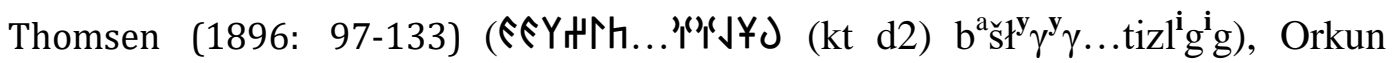

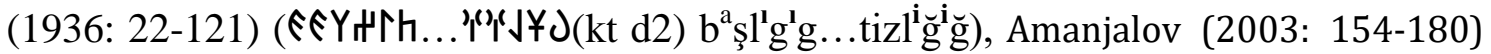

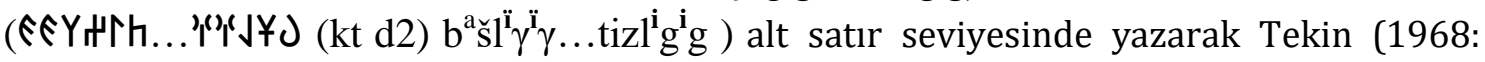

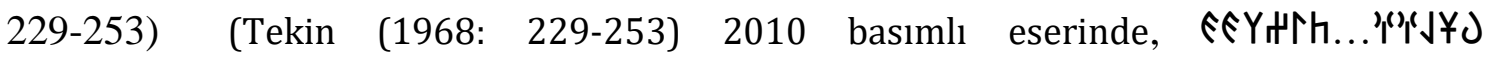
b(a)şl(1)g(1)g...tizl(i)g(i)g) ise yazılmayan sesleri parantez içine alarak yazılan ve yazılmayan harfleri ayrı ayrı transkribe etmişlerdir. Bu isimler dışındaki Türkologlar bu ayrıma dikkat etmemiştir.

SONUÇ 
Çuvaşça ve Yakutça dışında günümüzde yaşayan tüm çağdaş Türk dillerinin birincil yazılı kaynağı olan Orhun Yazıtları üzerine günümüze kadar birçok çalışma yapılmıştır. Çalışmalarda kullanılan transkripsiyonlar birbirlerinden farklılık gösterebilmektedir. $\mathrm{Bu}$ farklılıkların temel sebebi yazarların mensubu oldukları devletlerin kullanmış oldukları alfabe sistemlerinin farklı olmasıdır. Yazarların transkripsiyon metinleri incelendiğinde kiril ve latin harfli transkripsiyonlar karşımıza çıkmaktadır. Bunun dışında transkripsiyonu konusunda en çok ihtilaf bulunun işaretler; ünlü-ünsüz veya ünsüz-ünlü değerinde olan $\downarrow$, F-B, $\triangleleft, \boldsymbol{Y}$ harfler ve ligatür olarak tanımlanan $\mathbf{M}, 3,3$ birliktelikleri olarak karşımıza çıkmaktadır. Yapılacak yeni çalışmaların IPA standartlarına göre ve özellikle çift ses barındıran harflerdeki ses birlikteliklerini belirten işaretlerle gösterecek şekilde hazırlanmasının doğru olacağı görüşündeyiz.

\section{KAYNAKÇA}

Abdurrahmanov, G. \& Rustamov, A. (1982). Kadimgi Turkiy Til. Ukutuvchi Naşriyeti,Taşkent.

Amanzholov, A. S. (2003). History And Theory of Ancient Türkic Writing. Mektep, Almaty.

Aydarov, G. (1971). Yazık Orhonskih Pamyatnikov Drevnetyurkskoy Pis'mennosti VIII Veka. Alma-Ata: Nauka.

Aydın, E. (2017). Orhon Yazıtları (Köl Tegin, Bilge Kağan, Tonyukuk, Ongi, Küli Çor). İstanbul: Bilge Kültür Sanat.

Bazılhan, N. (2005). Kazakstan Tarihi Turalı Türki Derektemeleri II: Köne Türik Bitiktastarı Men Eskertkişteri (Orhon, Yenisey, Talas). Almatı: "Dayk-Press".

Berta, Á. (2010). Sözlerimi İyi Dinleyin: Türk ve Uygur Runik Yazıtlarının Karşıllaştırmalı Yayını (Çev. E. Yılmaz). Ankara: Türk Dil Kurumu Yayınları.

Ercilasun, A.B. (2016). Türk Kağanlığı ve Türk Bengü Taşları. İstanbul: Dergah Yayınları.

Ergin, M. (1978). Orhun Abideleri, Boğaziçi Yayınları. İstanbul: Boğaziçi Yayınları.

Gabain, A. (1950). Altürkishce Grammatik. Hamburg.

Geng, Sh. (2005). Gudai Tujue Wen Bei Ming Yanjiu [Eski Türk Yazıtları Araştırmaları], Beijing: Zhongyang Minzu Daxue Chubanshe. 2005. B. 94-223.

Guzev, V. \&, Klyaştornıy, G. (1995). Genel Yazı Nazariyesi Işığında Göktürk Yazısının Menşei Meselesi. TDAY Belleten, 27-33.

Hudiyev, N. (2015). Qadim Türk Yazılı Abidəlarinin Dili. Bakı.

Karcaubay, S. (2012). Orhon Muraları: II Kitap (Tüpnüska, Okılımı, Audarması, Tüsiniktemesi). Almatı: Abzal-Ay Baspası.

Malov, S. (1951). Pamyatniki Drevneturkskoy Pismennosti. İzdatelstvo Moskva: Akademik Nauk.

Radloff, W. (1899). Altürkischen Inschriften Der Mongolei, St. Petersburg, 1895. B. 5-83.

Melioranskiy, P. M., Pamyatnik v' Chest Ku'l Tegina, Tipografiya İmperatorskoy Akademii Nauk, St. Petersburg..

Orkun, H.N. (1936). Eski Türk Yazıtları, Ankara.

Recebov, E. \& Memmedov, J. (1993). Orxon Jenisey Abideleri. Bakı: Jazıçı.

Sıdıkov S. \& Konkobayev K. (2001). Bayırkı Türk Jazusuu (VII-X Qılımdar). Bişkek: KTMU.

Sodikov, K. (2004). Kük Türk Bitiglari: Matn va Uniך Tarixiy Talkini, Taşkent: Davlat Şarkşunoslik İnstituti Naşriyeti.

Şükürlü, Ә. (1993). Qədim Türk Yazılı Abidəlarinin Dili, Bakı: Maarif Nəşriyatı. 
Tekin, T. (1968). A Grammar Of Orkhon Turkic. Indiana University, Bloomington.

Tekin, T. (2010). Orhun Türkçesi Grameri. Ankara: TDK,.

Thomsen V. (1896). Inscriptions de l Orkhon Dechiffrees. Helsingfors.

Vambery, H. (1989). Noten Zu Den Alttürikchen Inschriften Der Mongolei and Sibiriens, Helsingfors.

(https://www.internationalphoneticassociation.org/content/full-ipa-chart) Alıntılama tarihi: 01.11.2021. 